\title{
Placenta Expulsion-time on Different Age and Breed Cows
}

\author{
Erif Maha Nugraha Setyawan ${ }^{1 *}$, Yosua Kristian Adi $^{1}$, Topas Wicaksono Priyo ${ }^{1}$, Surya Agus \\ Prihatno $^{1}$, Sri Gustari ${ }^{1}$, Asmarani Kusumawati ${ }^{1}$, Agung Budiyanto ${ }^{1}$ \\ ${ }^{1}$ Faculty of Veterinary Medicine, Universitas Gadjah Mada, Jl. Fauna No.2, Karangmalang, \\ Yogyakarta 55281, Indonesia
}

\begin{abstract}
The third stage of birth is placenta expulsion which can occur about 30 minutes after the release of the fetus but is more likely to occur between 180 to 300 minutes later. This research is expected to provide an understanding about the different time on placenta expulsion, the number of cotyledon and placenta weight that faced up by veterinarian. Cows with a body condition score between 2.5 to 3.5 and ready to give birth from various breeds were used in this study. The results showed that young cows $(<5$ years old; $366,50 \pm 30,97$ minutes) significantly had a longer placenta expulsion time than old cows ( $>5$ years old; $251,29 \pm 7,55$ minutes; $p<0,05$ ). While the amount of cotyledon and placenta weight did not differ between the two age groups. Based on breeds, the young Ongole cows showed significant different on placenta expulsion time compared with old ones $(397,25 \pm 61,60$ vs $250,80 \pm 14,79$ minutes; $p<0,05)$ but had no difference with the young and old crossbreed cows. Young cows need more time for placenta expulsion than the old ones and the young Ongole cows take the longest time compared to other age and breed groups.
\end{abstract}

\section{Introduction}

Birth or parturition is a physiological process associated with the production of fetuses and placentas from the mother [1]. The parturition process is generally aided by the strong motherhood of the uterine, abdominal, and diaphragm muscles [2]. Parturition activity is an ongoing process, but as a descriptive picture can be divided into 3 stages, namely the first stage (preparation stage, dilation), second stage (fetus expenditure), and third stage (placental expenditure). In general, almost all farm animals experience these stages, only the time required to complete each stage varies from species to species $[3,4]$.

At the stage of placental discharge there is a loss of circulation of the placenta and the placental villi fetus has degenerated. The degeneration process continues along with uterine contractions. After the fetus is born and the umbilical cord is severed, the volume of blood in the villi drops very quickly. Because the blood vessels do not contain blood, the villi become deflated and shrink [4]. Uterine and abdominal contractions continue but uterine contractions are not as strong at the stage of fetus production. This contraction of the uterus is not accompanied by contractions of the abdominal musculus and diaphragm. However

* Corresponding author: erif_maha@ugm.ac.id 
uterine contractions are strong enough to release the placenta from the endometrium as well as gradually decreasing uterine volume [5]. The separation of the placenta occurs at a time when the decrease in volume and contraction of the uterus that causes the endometrial crept (where the villi of the placenta is linked) to become superficial. This causes the placenta's villi to detach and bring the placenta closer to the cervix. The remains of the placenta and umbilical cord hanging on the lips of the vulva are heavy enough to pull the placenta out of the uterus [4]. After the placenta is removed, the cervix begins to secrete mucus that contains a lot of leukocytes. This mucus is quite thick and is a good blockage for the cervix so that the possibility of infection to the uterus from the vulva or vagina can be avoided $[4,5]$.

Placental discharge or expulsion (after birth) usually occurs about 30 minutes to 5 hours after the release of the fetus which regulated by the endocrine system. Under normal circumstances, the cotyledon which attached to the uterus, is separated allowing the membrane to come out through the birth canal. If the membrane is still not out after 24 hours, there is an abnormal condition, this needs to get attention because infection might be possible $[5,6]$.

Proper application of reproductive management is essential for high reproductive performance in cattle breeding efforts. One important parameter in reproductive management is the timing of placental discharge associated with uterine involution and subsequently affecting the postpartum estrus. The time analysis of placental expulsion in this study is expected to provide an understanding about the different time on placenta expulsion, the number of cotyledon and placenta weight that faced up by veterinarian. So that high livestock production figures can be achieved so that the objectives of meat self-sufficiency programs can be achieved and can also be obtained maximum profit for farmers.

\section{Materials and Methods}

\subsection{Materials}

Observations was conducted in several partner livestock groups of the Department of Reproduction and Midwifery in the Sleman and Kulon Progo areas. Cows used were cows from various breeds that are encountered and ready to give birth with a body condition score between 2.5 to 3.5. The age of the farm was based on the last artificial insemination record (AI) recorded on the AI card.

\subsection{Methods}

\subsubsection{Data Collection}

This research was conducted for 7 months from April to October by visiting selected livestock groups at the beginning of each month to survey cows with old farm that is at least 9 months 10 days so that it was expected to be observed the complete birth process in a not too long waiting time and obtained complete data on the parturition stage.

\subsubsection{Data Analysis}

The collected data were breed of cow, the age of the cow, the duration of the birth stage until the expulsion of the placenta. The data was analyzed with t-test two mean or if it can be 
grouped into 3 or more then Analysis of Variance (ANOVA) becomes the choice of Analysis method.

\section{Results and Discussions}

Cows that used in this study were 9 heads Peranakan Ongole (PO) and 4 heads crossed with Bos Taurus (Crossbreed). In addition to being grouped according to the breed, cows are analyzed by grouping 1 ) heifers with an age of less than 5.5 years and 2) old cows with an age of more than 5.5 years. Some cows have been pregnant and some were heifers. Mating is performed by means of artificial insemination (AI) and birth predictions are based on the recording on the AI card owned by the farmer.

Tabulation results and analysis using student t-test showed that heifers or under-5.5 years old significantly had a longer/longer placental discharge time than dean cows over the age of 5.5 years. While the number of cotyledons and placenta weight does not differ between the two age groups as can be seen in Table 1 below.

Table 1. Comparison of placental expenditure time, cotyledon count, and placental weight in heifers

\begin{tabular}{|c|c|c|c|}
\hline $\begin{array}{c}\text { Types of } \\
\text { Cows }\end{array}$ & $\begin{array}{c}\text { Placenta Expulsion } \\
\text { (minutes) }\end{array}$ & $\begin{array}{c}\text { Number of } \\
\text { Cotyledons (pieces) }\end{array}$ & $\begin{array}{c}\text { Placenta Weight } \\
\text { (kg) }\end{array}$ \\
\hline $\begin{array}{c}\text { Young } \\
(<5 \text { y.o. })\end{array}$ & $366,50 \pm 30,97^{\mathrm{a}}$ & $91,00 \pm 4,91$ & $4,38 \pm 0,36$ \\
\hline $\begin{array}{c}\text { Old } \\
(>5 \text { y.o. })\end{array}$ & $251,29 \pm 7,55^{\mathrm{b}}$ & $94,71 \pm 6,91$ & $3,79 \pm 0,42$ \\
\hline
\end{tabular}

Tabulation and analysis using ANOVA based on the breed of cows combined with the age of the mother cow showed that young Peranakan Ongole cows significantly experienced placental expenditure slower than young Peranakan Ongole cows. While the number of cotyledons and placenta weight does not differ between the four groups of breeds and ages as can be seen in Table 2 below. This indicates that young Peranakan Ongole cows have difficulty in the process of placenta production is possible due to the relatively smaller size of other breeds of cows. In addition, the size and type/breed of the calves also greatly affects the speed of placental expenditure.

Table 2. Comparison of placental expenditure time, cotyledon count, and placenta weight by age and breeds.

\begin{tabular}{|c|c|c|c|}
\hline $\begin{array}{c}\text { Types of } \\
\text { Cows }\end{array}$ & $\begin{array}{c}\text { Placenta Expulsion } \\
\text { (minutes) }\end{array}$ & $\begin{array}{c}\text { Number of } \\
\text { Cotyledons (pieces) }\end{array}$ & $\begin{array}{c}\text { Placenta Weight } \\
(\mathbf{k g})\end{array}$ \\
\hline $\begin{array}{c}\text { Young PO } \\
(<5 \text { y.o. })\end{array}$ & $397,25 \pm 61,60^{\mathrm{a}}$ & $87,75 \pm 13,82$ & $4,00 \pm 0,82$ \\
\hline $\begin{array}{c}\text { Old PO } \\
(>5 \text { y.o. })\end{array}$ & $250,80 \pm 14,79^{\mathrm{b}}$ & $88,00 \pm 13,58$ & $4,00 \pm 2,26$ \\
\hline $\begin{array}{c}\text { Young } \\
\text { Crossbreed } \\
(<5 \text { y.o. })\end{array}$ & $305,00 \pm 19,96^{\mathrm{ab}}$ & $97,50 \pm 4,95$ & $3,79 \pm 1,11$ \\
\hline $\begin{array}{c}\text { Old } \\
\text { Crossbreed } \\
(>5 \text { y.o. })\end{array}$ & $252,50 \pm 38,90^{\text {ab }}$ & $111,50 \pm 21,92$ & $5,25 \pm 0,35$ \\
\hline \multicolumn{2}{|c|}{ a, b Within a column, values with different superscript letters are significantly different $(\mathrm{p}<0.05)}$. \\
\hline
\end{tabular}


Observations were made for several days in a row to see the condition of the cow before the parturition. In general, the cow looks calm and the appetite remains good until the approach of the parturition. The cow is restless, the frequency of breath increases, the temperature decreases and looks more alert.

Observation of parturition process was carried out by external inspection including general conditions, behavior, appetite, pelvis, vulva, vagina, udder and nipple, fetus movement, uterine contractions, and mucus discharge. The observed cow shows an expression of alertness and the cow begins to look restless by being marked ventral recumbency and then standing back accompanied by the discharge of fetal fluid. This condition lasts several days where the cow gets restless which was characterized by kicking the stomach. The frequency of laying and discharge of fetal fluid was increasingly characterized also by cows tackling their tails and the frequency of cow breath is seen so quickly.

The third stage is the discharge of the fetal or placental membrane within 12 hours after birth. If the placenta is discharged for more than 12 hours, it means that the cow has placental retention. Placenta production is influenced by several factors, including uterine and abdominal contractions that continue until the placenta can expulsed [3]. For example: the placenta starts out at 4:45 p.m. and the entire placenta comes out at 9:12 p.m. ( \pm 4.5 hours). This is normal when compared to literature. Once the placenta comes out completely, we perform a placentome count. The placentas we counted amounted to 92 pieces. According to Noakes et al. [6] the number of bovine placentas is 60-120 pieces. Based on the literature, it can be said that the number of beef placentas is normal. In conclusion, Young cows need more time for placenta expulsion than the old ones and the young Ongole cows take the longest time compared to other age and breed groups.

\section{References}

1. P.G.G. Jackson, Handbook Obstetri Veteriner $2^{\text {nd }}$ ed. (2004)

2. D. Manan, Ilmu Kebidanan pada Ternak (2001)

3. P.J.H. Ball and A.R. Peters, Reproduction in Cattle $3^{\text {rd }}$ ed. (2004)

4. D. Weststeyn, Activity and Rumination Monitoring for Calving Times (2011)

5. T.D. Lestari, Ismudiono. Ilmu Reproduksi Ternak (2013)

6. D. E. Noakes, T. J. Parkinson, and G.C.W. England, Arthur's Veterinary Reproduction and Obstetrics $8^{\text {th }}$ ed. (2001) 